\title{
Development of a field-friendly automated dietary assessment tool and nutrient database for India
}

\author{
Carrie R. Daniel ${ }^{1,2}$, Kavita Kapur ${ }^{3}$, Mary J. McAdams ${ }^{4}$, Sujata Dixit-Joshi ${ }^{5}$, Niveditha Devasenapathy ${ }^{6}$, \\ Hemali Shetty $^{7}$, Sriram Hariharan ${ }^{8}$, Preethi S. George ${ }^{9}$, Aleyamma Mathew ${ }^{9}$ and Rashmi Sinha ${ }^{1 *}$ \\ ${ }^{1}$ Nutritional Epidemiology Branch, Division of Cancer Epidemiology and Genetics, National Cancer Institute, \\ NIH, 6120 Executive Boulevard, Suite 320, Rockville, MD 20852, USA \\ ${ }^{2}$ Department of Epidemiology, Division of Cancer Prevention and Population Sciences, \\ The University of Texas M.D. Anderson Cancer Center, Houston, TX, USA \\ ${ }^{3}$ Steno Diabetes Center, Gentofte, Denmark \\ ${ }^{4}$ Information Management Services, Silver Spring, MD, USA \\ ${ }^{5}$ Westat, Rockville, MD, USA \\ ${ }^{6}$ Centre for Chronic Disease Control, New Delhi, India \\ ${ }^{7}$ Healis Sekhsaria Institute for Public Health, Navi Mumbai, India \\ ${ }^{8}$ Atribs IT Consulting, Chennai, India \\ ${ }^{9}$ Regional Cancer Center, Trivandrum, Kerala, India
}

(Submitted 28 May 2012 - Final revision received 30 April 2013 - Accepted 3 May 2013 - First published online 26 June 2013 )

\begin{abstract}
Studies of diet and disease risk in India and among other Asian-Indian populations are hindered by the need for a comprehensive dietary assessment tool to capture data on the wide variety of food and nutrient intakes across different regions and ethnic groups. The nutritional component of the India Health Study, a multicentre pilot cohort study, included 3908 men and women, aged 35-69 years, residing in three regions of India (New Delhi in the north, Mumbai in the west and Trivandrum in the south). We developed a computer-based, intervieweradministered dietary assessment software known as the 'NINA-DISH (New Interactive Nutrition Assistant - Diet in India Study of Health)', which consisted of four sections: (1) a diet history questionnaire with defined questions on frequency and portion size; (2) an open-ended section for each mealtime; (3) a food-preparer questionnaire; (4) a $24 \mathrm{~h}$ dietary recall. Using the preferred meal-based approach, frequency of intake and portion size were recorded and linked to a nutrient database that we developed and modified from a set of existing international databases containing data on Indian foods and recipes. The NINA-DISH software was designed to be easily adaptable and was well accepted by the interviewers and participants in the field. A predominant three-meal eating pattern emerged; however, patterns in the number of foods reported and the primary contributors to macro- and micronutrient intakes differed by region and demographic factors. The newly developed NINA-DISH software provides a much-needed tool for measuring diet and nutrient profiles across the diverse populations of India with the potential for application in other South Asian populations living throughout the world.
\end{abstract}

Key words: Computer-assisted interviews: Diet histories: Nutrient databases: Asian-Indian foods

Epidemiological investigations of diet in India are rare and appear to be hindered by insufficient dietary assessment tools and nutrient databases to capture data on the wide variety of Asian-Indian foods and regional recipes. The ongoing epidemic of diabetes and other diet-related chronic diseases burdening Asian-Indian populations within India and abroad $^{(1-3)}$ cannot be adequately addressed without widely applicable and effective research tools to measure dietary intakes in these at-risk populations. Diverse dietary practices linked to India's unique religious and socioeconomic heterogeneity may provide information on a wide range and variety of food and nutrient intakes as well as on vegetarian diets and use of distinctive spices, oils and pulses ${ }^{(4-6)}$. Such data could provide insights into diet-disease relationships and contribute to the development and refinement of international dietary recommendations with

Abbreviations: $24 \mathrm{HR}$, multiple $24 \mathrm{~h}$ recalls; DHQ, diet history questionnaire; IHS, India Health Study; NINA-DISH, New Interactive Nutrition Assistant - Diet in India Study of Health.

*Corresponding author: R. Sinha, email sinhar@exchange.nih.gov 
a stronger emphasis on health promotion and disease prevention globally.

In an effort to begin to address these needs, we conducted a multicentre pilot study designed to assess the feasibility of establishing a prospective diet and cancer cohort, known as the India Health Study (IHS ${ }^{(7,8)}$ ). Although other methods of diet assessment were available at the time ${ }^{(9-19)}$, none adequately captured data on Indian foods, particularly local and regional foods; Indian nutrient databases ${ }^{(13,20,21)}$ either were out of date or included information on only a limited number of common foods and recipes. The overall objective of the nutritional component of the IHS was to develop and test a modern and adaptable dietary assessment instrument that could be easily implemented in the field, but would also comprehensively capture the regional, ethnic, religious and socio-economic heterogeneity of dietary habits within India. Herein, we describe the development of a simple but flexible software program to assess habitual diets via complementary platforms (diet history questionnaire (DHQ) and multiple $24 \mathrm{~h}$ recalls $(24 \mathrm{HR})$ ), the necessary details it can collect and how we created a collated nutrient database of regional Indian foods and recipes. We also provide preliminary data that are useful to make decisions on the type of dietary instrument to use in the Indian population as well as future studies of South Asians.

\section{Methods}

\section{Study subjects}

The IHS was a multicentre pilot study designed to investigate the feasibility of establishing a diet and cancer cohort in India, and it has been described in detail elsewhere ${ }^{(7,8)}$. Briefly, the study was conducted between December 2006 and July 2008 in participating centres spread across three regions of India: New Delhi in the north (All India Institute of Medical Sciences and Centre for Chronic Disease Control), Mumbai in the west (Healis-Sekhsaria Institute for Public Health) and Trivandrum in the south (Regional Cancer Center). Centres were selected in areas with established cancer registries and to capture a range of different economic, ethnic and urbanisation patterns ${ }^{(7,8)}$. The household sampling scheme has been described in detail elsewhere ${ }^{(7)}$. Briefly, we recruited diverse religious groups known to follow varied patterns of diet and lifestyle practices and targeted both urban and rural areas in Trivandrum. Healthy adults (aged 35 to 69 years) proficient in English or regional language were eligible to participate and provided sociodemographic, diet and other lifestyle information upon enrolment via interviews conducted by trained field staff in their homes. Of the 4177 eligible IHS participants, $94 \%$ ( $n$ 3908) completed the DHQ. Fig. 1 shows the number of participants for the other nutritional components. Following further data cleaning, eight participants were excluded from the DHQ analysis ( $n$ 3900) for reporting less than ten total food items in the DHQ. An additional thirty-eight participants ( $n$ 3862) were excluded from the nutrient analysis due to improbable total energy intake (outside of three standard deviations). The present study was conducted according to the guidelines laid down in the Declaration of Helsinki, and all procedures involving human subjects were approved by the human ethics committees from each study centre, the Special Studies Institutional Review Board of the US National Cancer Institute and the Indian Health Ministry Screening Committee (part of the Indian Council of Medical Research reporting to the Government of India).

\section{Dietary assessment}

The New Interactive Nutrition Assistant - Diet in India Study of Health (NINA-DISH) software (Fig. 2), which was adapted from the software originally developed by Novo Nordisk Pharma India ${ }^{(22)}$, is designed such that it can be ported into any database with minimal modification. The application was designed using the following three approaches: User Interface; Business Logic; the Database. It was developed using the DOTNET FRAMEWORK version 1.1 (Microsoft Corporation) C and ASP.NET Languages (Microsoft Corporation) and MS SQL SERVER (Microsoft Corporation) and ORACLE as DATABASE (Oracle RDBMS; Oracle Corporation).

The NINA-DISH software consists of four sections: (1) defined questions on frequency and portion size, similar to a FFQ; (2) an open-ended section for each mealtime; (3) a food-preparer questionnaire; (4) a $24 \mathrm{~h}$ dietary recall. The DHQ comprised the first two sections and was specifically designed to collect comprehensive dietary intake data over the past year in IHS participants residing in the three different regions.

Diet history questionnaire. In the developmental phase, small pilot studies were conducted in each of the three regions to develop region-specific food lists for the DHQ component. In a convenience sample of approximately twenty to thirtyfive individuals in each region, $24 \mathrm{HR}$ were administered to identify the most commonly consumed foods and beverages at various mealtimes and snack times, as well as potential seasonal variation in fruit and vegetable intakes. A meal-based approach was found to be more user-friendly for the interviewers and cognitively acceptable for the participants in this population. Other cognitive studies of a computerised dietary recall in the USA have also revealed a strong preference for a meal-based approach ${ }^{(23)}$, as it helps the participants to first relate to a meal occasion, for example, breakfast, and then to access and select the foods from their memory that they typically eat for breakfast. While designing the software, it was also more advantageous to include certain foods typically associated with a particular meal in a drop-down menu rather than searching the full database (Fig. 3). However, in India, people tend to eat similar food items across different meal occasions throughout the day (e.g. rice), as reflected in the overall limited number of food items reported (Table 1). The NINA-DISH software also allowed the interviewers to link the same food items consumed at multiple meal occasions throughout the day.

The final version of the software for the DHQ queried dietary intake over the past year and included a selection of 910 food items over eight mealtimes (bed tea, breakfast, 


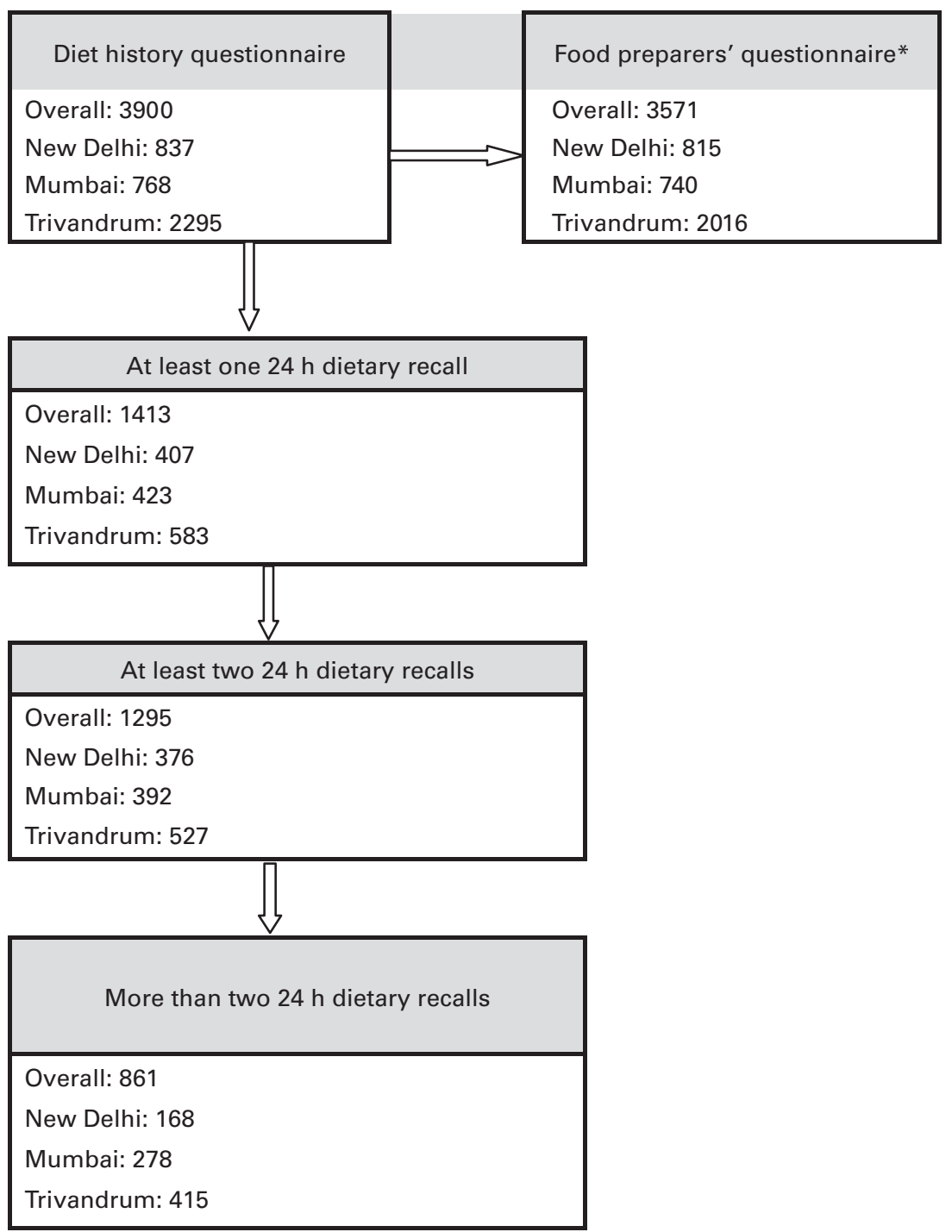

Fig. 1. Number of the India Health Study participants who completed the diet history questionnaire, $24 \mathrm{~h}$ dietary recall and food-preparer questionnaire. *Food preparers' information from the number of households (Delhi: $n$ 815; Mumbai: $n$ 629; Trivandrum: $n$ 2016).

mid-morning snack, lunch, afternoon tea, evening snack, dinner and bed time snack; Figs. 2 and 3). Items displayed in the drop-down menu were customised for each region, and the number of additional queries also varied between regions from 157 to 216. An open-ended section with prompts for each mealtime was also included in the software to allow the participants to provide information on other food items that were not included in the DHQ's predefined lists or drop-down menu.

The DHQ was structured to first capture data on the type of food consumed at each mealtime (e.g. fruit), followed by details of the individual type of food (e.g. banana), frequency of consumption (e.g. daily, weekly and monthly) and the quantity or portion size (Fig. 2). A sample of questions included in the DHQ is shown in Fig. 3. For some of the questions, we followed the nesting approach ${ }^{(23)}$ of asking about the addition of a food item in relation to the main food (e.g. the addition of milk and sugar to tea). The interviewers provided standard props to aid the participants in portion size estimation (Fig. 4). These included different sizes and types of household measures, such as glasses, katoris (bowls) and spoons, as well as cardboard cut-outs (e.g. five sizes for chapatti/dosa/paratha) and fruit photographs (three sizes: small, medium and large). The final section of the DHQ specifically queried about the intake of sweets and the use of multivitamins and mineral and herbal supplements, as well as Ayurvedic medicines.

The software was also designed to facilitate simple dietary analyses and food group comparisons. Responses to the DHQ were linked to a food database classified into twenty general food groups (i.e. beverages; cereals; chutney, soups and condiments; confectioneries, syrups and chocolates; curry vegetables; dry vegetables; fast food; fats and oil; fruit; green vegetables; juice and soft drinks; liquor; meat, fish and chicken; milk; nuts; pulses; salad; savoury snacks; sugar, honey and molasses; and sweet snacks). Food items under 


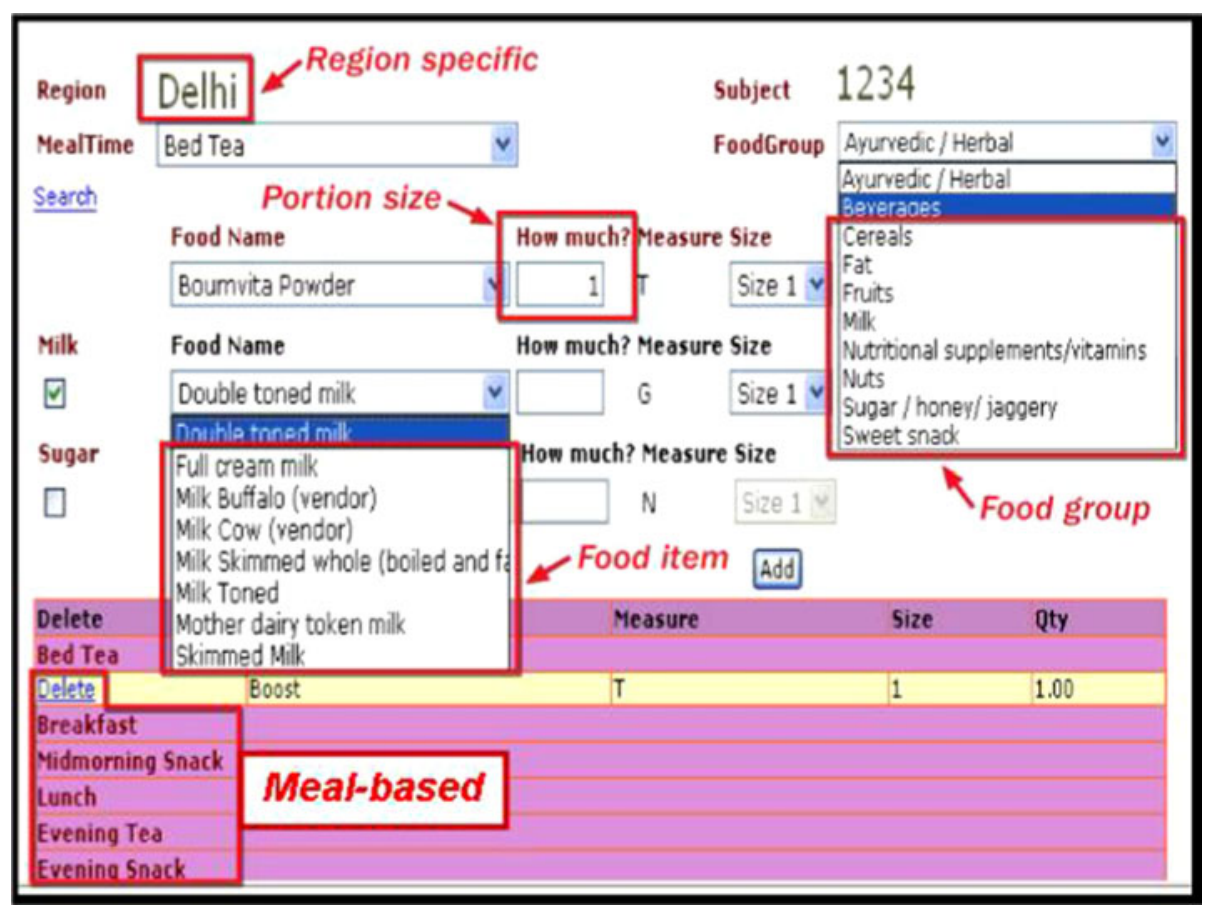

Fig. 2. Details of the NINA-DISH (New Interactive Nutrition Assistant - Diet in India Study of Health) software. (A colour version of this figure can be found online at http://www.journals.cambridge.org/bjn)

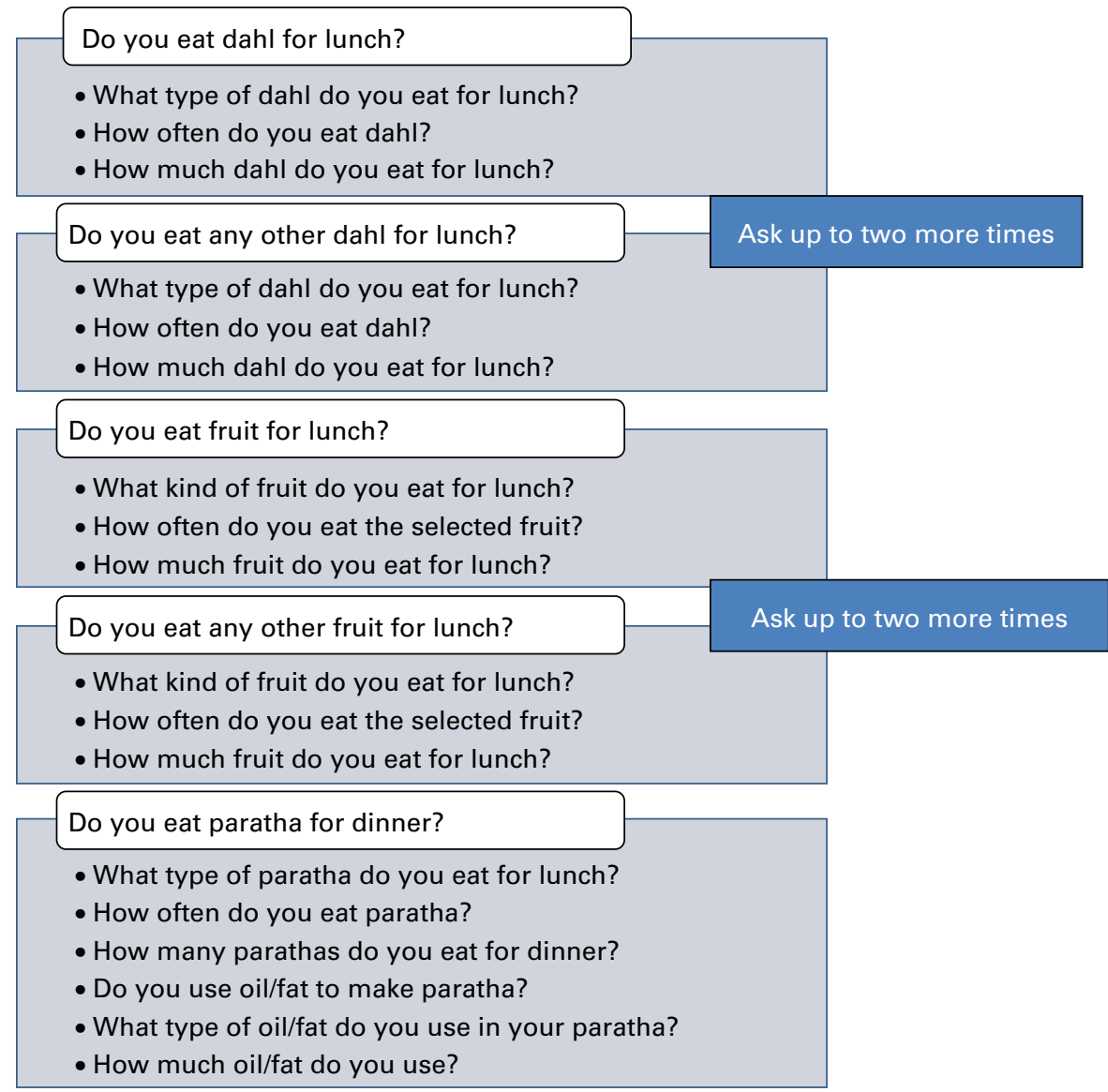

Fig. 3. Sample of questions included in the diet history questionnaire. (A colour version of this figure can be found online at http://www.journals.cambridge.org/bjn) 
Table 1. Number of food items queried and reported in the diet history questionnaire (DHQ) and $24 \mathrm{~h}$ recalls (24HR) (Medians with their 10th and 90th percentiles)

\begin{tabular}{|c|c|c|c|c|c|c|c|c|c|}
\hline & \multicolumn{3}{|c|}{ Delhi ( $n$ 837) } & \multicolumn{3}{|c|}{ Mumbai ( $n 768)$} & \multicolumn{3}{|c|}{ Trivandrum (n 2295) } \\
\hline & \multirow[b]{2}{*}{$\begin{array}{l}\text { No. of food items } \\
\text { in the } \mathrm{DHQ}\end{array}$} & \multicolumn{2}{|c|}{$\begin{array}{l}\text { No. of food items } \\
\text { reported }^{*}\end{array}$} & \multirow[b]{2}{*}{$\begin{array}{l}\text { No. of food items } \\
\text { in the } \mathrm{DHQ}\end{array}$} & \multicolumn{2}{|c|}{$\begin{array}{l}\text { No. of food items } \\
\text { reported }^{*}\end{array}$} & \multirow[b]{2}{*}{$\begin{array}{l}\text { No. of food items } \\
\text { in the } \mathrm{DHQ}\end{array}$} & \multicolumn{2}{|c|}{$\begin{array}{l}\text { No. of food items } \\
\text { reported }\end{array}$} \\
\hline & & Median & $\begin{array}{l}\text { 10th-90th } \\
\text { percentile }\end{array}$ & & Median & $\begin{array}{l}\text { 10th-90th } \\
\text { percentile }\end{array}$ & & Median & $\begin{array}{l}\text { 10th-90th } \\
\text { percentile }\end{array}$ \\
\hline \multicolumn{10}{|l|}{ DHQ } \\
\hline Bed tea & 5 & 1 & $0-2$ & 4 & 0 & $0-1$ & 5 & 1 & $1-1$ \\
\hline Breakfast & 23 & 10 & $4-16$ & 24 & 6 & $2-11$ & 24 & 11 & $7-13$ \\
\hline Mid-morning snack & 8 & 0 & $0-3$ & 25 & 0 & $0-1$ & 13 & 0 & $0-1$ \\
\hline Lunch & 28 & 15 & $9-21$ & 36 & 27 & $14-36$ & 30 & 16 & $10-21$ \\
\hline Afternoon tea & 5 & 0 & $0-2$ & 25 & 2 & $0-4$ & 13 & 1 & $0-4$ \\
\hline Evening snack & 13 & 4 & $0-7$ & 18 & 0 & $0-4$ & 14 & 1 & $0-5$ \\
\hline Dinner & 29 & 14 & $8-22$ & 36 & 25 & $14-39$ & 30 & 9 & $2-17$ \\
\hline Bedtime snack & 5 & 0 & $0-1$ & 5 & 0 & $0-0$ & 5 & 0 & $0-1$ \\
\hline $\begin{array}{l}\text { Sweets, herbals and } \\
\text { supplements }\end{array}$ & 5 & 2 & $0-3$ & 5 & 1 & $0-3$ & 5 & 1 & $0-4$ \\
\hline \multirow[t]{2}{*}{$24 \mathrm{HR}$} & & \multicolumn{2}{|c|}{$\begin{array}{l}\text { No. of food items } \\
\text { reported }(n 407)\end{array}$} & & \multicolumn{2}{|c|}{$\begin{array}{l}\text { No. of food items } \\
\text { reported ( } n \text { 423) }\end{array}$} & & \multicolumn{2}{|c|}{$\begin{array}{l}\text { No. of food items } \\
\text { reported ( } n 583)\end{array}$} \\
\hline & & Median & $\begin{array}{l}\text { 10th-90th } \\
\text { percentile }\end{array}$ & & Median & $\begin{array}{l}\text { 10th-90th } \\
\text { percentile }\end{array}$ & & Median & $\begin{array}{l}\text { 10th-90th } \\
\text { percentile }\end{array}$ \\
\hline Bed tea & & 1.0 & $0.5-1.8$ & & 0.0 & $0.0-0.0$ & & $1 \cdot 0$ & $0.5-1.5$ \\
\hline Breakfast & & 2.5 & $2 \cdot 0-3 \cdot 0$ & & $2 \cdot 0$ & $1 \cdot 0-2 \cdot 7$ & & $2 \cdot 3$ & $1 \cdot 3-3 \cdot 0$ \\
\hline Mid-morning snack & & 0.8 & $0.0-1.5$ & & 0.0 & $0.0-1.3$ & & 0.0 & $0.0-1.0$ \\
\hline Lunch & & 3.3 & $2 \cdot 5-4.0$ & & $3 \cdot 3$ & $2 \cdot 3-4 \cdot 5$ & & 4.0 & $2.5-5.5$ \\
\hline Afternoon tea & & 0.5 & $0.0-1.5$ & & 1.0 & $0.0-1.8$ & & 0.8 & $0.0-1.5$ \\
\hline Evening snack & & 1.0 & $0.0-1.8$ & & 0.0 & $0.0-1.5$ & & 0.5 & $0.0-1.5$ \\
\hline Dinner & & 3.0 & $2.0-3.5$ & & 3.5 & $2.5-4.5$ & & $2 \cdot 8$ & $1 \cdot 8-4 \cdot 0$ \\
\hline Bedtime snack & & 0.0 & $0.0-0.5$ & & 0.0 & $0.0-0.0$ & & 0.0 & $0.0-0.3$ \\
\hline
\end{tabular}

*Main food items only, excluding foods used with main items (e.g. milk and sugar used with tea). 


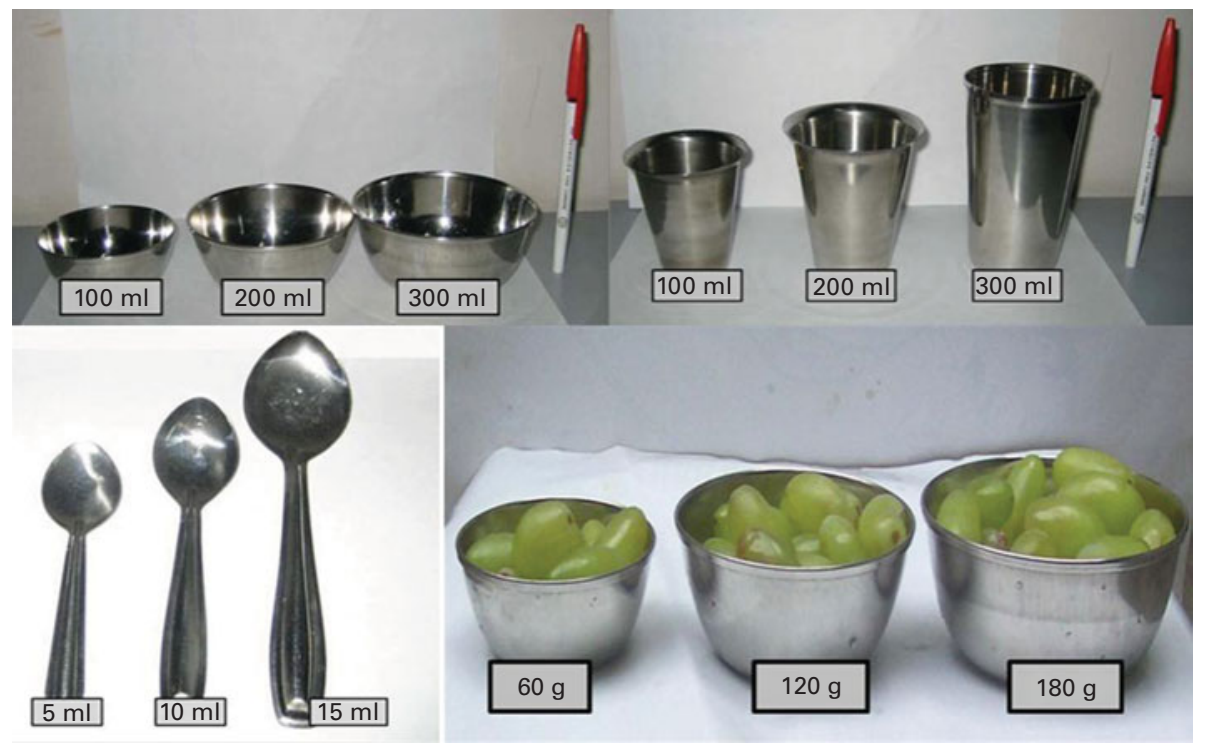

Fig. 4. Utensils and food models for capturing dietary data. (A colour version of this figure can be found online at http://www.journals.cambridge.org/bjn)

each of these groups were further categorised and coded into a total of twelve broader 'food categories' (Appendix 1, available online). For example, we can evaluate total cereal or subgroups of cereals, such as wheat and rice, separately or be more specific and evaluate fermented rice. Similarly, for vegetables, we can evaluate total vegetables or cruciferous $v$. allium vegetables ${ }^{(24)}$.

Food-preparer questionnaire. A detailed description of the food-preparer component of the NINA-DISH software is available elsewhere ${ }^{(25)}$. Briefly, this portion of the computerassisted interview was completed by the individual within the household who was primarily responsible for purchasing and preparing food for the family. This novel method for assessing food items primarily added during cooking allowed us to estimate per capita consumption of nineteen spices, chilies, coconuts, garlic, onions and thirteen cooking oils among 3625 participants.

$24 \mathrm{~h}$ recall. The computer-assisted $24 \mathrm{HR}$ was designed to collect data on food and beverage intakes, as well as portion size, for the day before the interview, starting from the time the participants woke up in the morning until the time they went to bed. In order to better understand the eating habits of the study population, we designed the $24 \mathrm{HR}$ component to first record the different times the participants ate throughout the day, followed by queries on what type of meal they ascribed to that eating occasion. For example, many working Indians consume a main meal akin to a lunch at 09.00 hours, but only a snack at 'lunchtime'. As in the DHQ, the foods were classified into eight mealtimes with the appropriate food options readily available from the drop-down menu. To account for variation in dietary intakes by season and day of the week (weekday $v$. weekend), up to four recalls over three weekdays and one weekend were administered to a subset of the participants during a six-month period (Fig. 1).

\section{Nutrient database}

There is no single up-to-date and comprehensive Indian food and nutrient database currently available for estimating the nutrient values of regional Indian foods ${ }^{(5)}$; thus, to create a single, cohesive NINA-DISH nutrient database, we pooled the relevant data from seven international databases we identified that contained data on Indian foods and recipes in 2009 (Appendix 2, available online). Given the wide variety of foods reported by the study participants and to fill critical gaps, IHS investigators also carried out additional reconstruction and updating of Indian recipes.

The process of compiling the NINA-DISH database is shown in Fig. 5. As we had to use databases from several different countries containing information on similar Indian foods, we developed matching criteria to select the most culturally relevant representative of a regional food or recipe preparation. Many of the pre-existing databases that we identified represented countries where Indians from particular regions commonly immigrate. For example, the nutrient databases of Malaysia or Singapore are more likely to reflect the ingredients and regional cooking practices of Trivandrum (e.g. payasam, murukku and masala dosa), while the UK database is more likely to reflect the ingredients and regional cooking practices of New Delhi and Mumbai (e.g. chana, aloo-matar and khichdi). Additionally, the US database and the Food and Nutrition Database for Dietary Studies (FNDDS) were used for items common to the three regions (e.g. fruit juice, eggs and doughnut). Additionally, we developed a total of thirty-five recipes (e.g. avial, bhel-puri, pav bhaji, pani puri, modak and modakam, puran poli and several types of appams), as we could not source reasonable data for these foods in the available databases. Although we found it necessary to develop recipes for all the three regions, we found the current databases to be the most lacking with regard to data on the 


\begin{tabular}{|c|c|c|c|}
\hline \multicolumn{4}{|c|}{ Number of foods reported by IHS participants } \\
\hline \multicolumn{4}{|l|}{$\begin{array}{l}\text { New Delhi: } 211 \\
\text { Mumbai: } 337 \\
\text { Trivandrum: } 315\end{array}$} \\
\hline \multicolumn{4}{|l|}{$\sqrt{3}$} \\
\hline \multicolumn{4}{|c|}{ Nutrient databases (7) containing foods reported by IHS participants } \\
\hline $\begin{array}{l}\text { UK: } 214 \text { foods } \\
\text { FNDDS: } 184 \text { foods }\end{array}$ & \multicolumn{3}{|c|}{$\begin{array}{l}\text { Database for } \\
\text { New Delhi and Mumbai }\end{array}$} \\
\hline $\begin{array}{l}\text { Singapore: } 74 \text { foods } \\
\text { Malaysia: } 25 \text { foods }\end{array}$ & \multicolumn{3}{|c|}{ Database for Trivandrum } \\
\hline $\begin{array}{l}\text { NUTTAB (Australia): } 14 \\
\text { foods } \\
\text { USDA: } 14 \text { foods } \\
\text { Worldfood: five foods }\end{array}$ & \multicolumn{3}{|c|}{$\begin{array}{l}\text { Back-up nutrient databases for } \\
\text { all the three IHS regions }\end{array}$} \\
\hline \multicolumn{4}{|c|}{ Number of regional IHS foods linked with specific nutrient databases } \\
\hline \multirow{2}{*}{ Nutrient database } & \multicolumn{3}{|l|}{ IHS region } \\
\hline & New Delhi & Mumbai & Trivandrum \\
\hline UK & 36 & 97 & 15 \\
\hline FNDDS & 49 & 58 & 68 \\
\hline Singapore & 7 & 22 & 45 \\
\hline Malaysia & 6 & 4 & 15 \\
\hline NUTTAB & 8 & 2 & 4 \\
\hline USDA & 1 & 7 & 6 \\
\hline WorldFood & 1 & 4 & 0 \\
\hline None, recipes developed & 4 & 15 & 16 \\
\hline
\end{tabular}

Fig. 5. Identification and selection of nutrient databases for the foods reported by the India Health Study (IHS) participants. FNDDS, Food and Nutrition Database for Dietary Studies; NUTTAB, Nutrition Tables; USDA, US Department of Agriculture.

foods reported in Trivandrum. For each nutrient, we used a standardised unit of measurement and reported values per $100 \mathrm{~g}$ of the edible portion of the food product ${ }^{(26,27)}$.

Quality control. Many layers of quality-control steps were instituted to minimise possible errors in data collection and analysis. The study nutritionist trained field staff in interview techniques for dietary assessment and use of food models for assessing portion sizes and unique regional food items. Each interviewer was required to have working knowledge of computers to operate the NINA-DISH software on portable laptops. During the field component of the study, project leaders made unannounced visits to observe the interviews being conducted. Each $24 \mathrm{HR}$ was checked by the study nutritionists after it was collected, and any questionable entry was re-queried. Daily random checks for errors were also done for the DHQ. In preparation for analysis, the dietary data were edited to revise updated food items, resolve duplicated entries and identify new foods for review and inclusion in the nutrient database. Field and cross-field checks were also done to identify problematic values or inconsistencies in the data items being analysed.

\section{Statistical analysis}

Descriptive statistics by region, including means, medians, and 10th and 90th percentiles, were generated using the PROC MEANS and PROC UNIVARIATE procedures in SAS version 9.1.3 (SAS Institute, Inc.). 


\section{Results}

Table 1 reports the number of foods queried and reported in the DHQ and $24 \mathrm{HR}$ by region and mealtime. In all the regions, the greatest numbers of food items were reported for the three main meals, namely breakfast, lunch and dinner. Participants in New Delhi appeared to consume slightly more foods between main meals, while consuming a mid-morning or an evening snack was rare in Mumbai and Trivandrum. Including more food items in the DHQ queries (tailored to each region to capture data on unique regional foods) resulted in a greater number of foods being reported. Including repeat queries for certain foods (as shown in Fig. 3) increased the number of food items being reported substantially (i.e. 30.1\% for Delhi, $44.9 \%$ for Mumbai and $12.4 \%$ for Trivandrum).

Table 2 reports the number of food items reported and time taken to complete the DHQ and $24 \mathrm{HR}$ by various demographic factors. Across all the regions, the DHQ was generally completed within $20 \mathrm{~min}$ to $1 \mathrm{~h}$, while a single $24 \mathrm{HR}$ was generally completed by the interviewer and participant within $10 \mathrm{~min}$ or less. The number of food items reported and the median time taken for the participants to complete the DHQ and $24 \mathrm{HR}$ interview varied by age, sex, income or education level. Patterns in the number of food items by region, mealtime and demographic factors were similar between the DHQ and 24HR. Across the three regions, the participants reported a total of 576 unique food items (Fig. 5).

The top five foods that contributed to the derived nutrient values in this population are provided in Table 3. Commonly consumed foods across all the three regions, such as roti (a flat wheat bread), rice and mixed-curry dishes, contributed largely to macronutrient intake, but we also observed regional differences. For example, in Trivandrum, 35\% of total energy intake was captured with the assessment of rice intake, while in New Delhi, 28\% of total energy intake came from roti. In Mumbai, major contributors to total energy intake were more varied, with roti and rice contributing 13 and $8 \%$, respectively. The contributions of meat or fish to nutrient intake also revealed interesting regional differences. For example, fish dishes were a key contributor to the intake of several essential macro- and micronutrients in Trivandrum, while dairy products were unique contributors in New Delhi. Food contributors to nutrient values did not differ substantially by sex (data not shown).

\section{Discussion}

To facilitate epidemiological research on diet and disease risk in India, we developed and tested a comprehensive dietary assessment tool to capture data on food and nutrient intakes within three diverse regions of India. In the developmental phase, we identified a number of unique regional foods and found that a meal-based approach was more user-friendly for the interviewers and cognitively acceptable for the participants. In the field, the interactive NINA-DISH software allowed the field staff of the IHS to successfully and efficiently collect dietary data via computer-assisted, in-person interviews. The comprehensive nature of the pilot study resulted in the inclusion of over 1000 unique foods and mixed dishes across the three regions; however, the software can be easily adapted to include additional new food items. We found informative differences in the number of food items reported at different times of the day and in the time needed to complete the DHQ and $24 \mathrm{HR}$ among different sociodemographic groups. Using a nutrient database that we developed by collating and updating data from several international resources, we identified major food contributors to nutrient intake across the regions, which provided practical information on the most important food items to assess within the Indian population.

We found the meal-based approach for the NINA-DISH software to be particularly useful and informative in this population. Although this requires more time than that required to complete a food-based FFQ from the respondent, it provides more cognitive support for the recall process, particularly when interviewer administered and combined with a nesting approach ${ }^{(28-30)}$. In conjunction with the meal-based approach, the $24 \mathrm{HR}$ and the open-ended queries in the DHQ provided the participants an opportunity to ascribe foods to a particular mealtime and to report foods that were not in the database. This provided useful information to improve the efficiency and performance of the NINA-DISH software, which is easily modified, adapted and updated.

A predominant three-meal eating pattern emerged with some differences by region and demographic factors including age, income and urban-rural residence. The difference in the number and type of foods reported by the participants in the DHQ and $24 \mathrm{HR}$ was probably due to several factors. Differences in the number of food items across demographic factors may reflect differences in access to food and other resources, as the present results suggested that individuals of higher socio-economic status and younger age and/or living in an urban area consumed a wider variety of foods. However, participants in all the three regions did not eat a large variety of foods during the day and also appeared to eat many of the same foods during different meal occasions. For example, rice or roti may be typically eaten at breakfast, lunch and dinner, and snacking between meals was relatively infrequent.

No single nutrient database available was adequate to capture up-to-date and comprehensive nutrient profiles of local Indian foods and regional dishes. Thus, the nutrient database for the present study was compiled from various nutrient databases throughout the world containing data on South Asian or Asian-Indian foods. Although recent nutrient data for India are limited, the food and nutrient profiles that we found in the Indian population ${ }^{(7,24)}$ are generally in line with other published studies of dietary intakes conducted in India ${ }^{(31-34)}$ Staple carbohydrate dishes were the primary contributors to total energy intake across each of the regions and corroborate the starch-based nature of the Indian diet ${ }^{(31,33)}$. Within South Asian populations, both an excess and a deficiency of nutrients have been associated with highly prevalent risk factors for chronic diseases, such as insulin resistance, dyslipidaemia and inflammation ${ }^{(31,33,35)}$. More specifically, dietary concerns include a low intake of 'good fats' (MUFA and $n$-3 PUFA) and fibre, combined with a high intake of 'bad fats' (mainly 
Table 2. Number of food items reported and time taken to complete the diet history questionnaire (DHQ) and $24 \mathrm{~h}$ recalls (24HR) by demographic factors (Medians with their 10th and 90th percentiles)

\begin{tabular}{|c|c|c|c|c|c|c|c|c|c|c|}
\hline & \multicolumn{5}{|c|}{$\mathrm{DHQ}$} & \multicolumn{5}{|c|}{$24 \mathrm{HR}^{*}$} \\
\hline & \multirow[b]{2}{*}{$\begin{array}{l}\text { Sample } \\
\text { size }\end{array}$} & \multicolumn{2}{|c|}{ No. of total food items } & \multicolumn{2}{|c|}{$\begin{array}{l}\text { No. of minutes taken } \\
\text { to complete }\end{array}$} & \multirow[b]{2}{*}{$\begin{array}{l}\text { Sample } \\
\text { size }\end{array}$} & \multicolumn{2}{|c|}{ No. of food items } & \multicolumn{2}{|c|}{$\begin{array}{l}\text { No. of minutes taken } \\
\text { to complete }\end{array}$} \\
\hline & & Median & $\begin{array}{l}\text { 10th-90th } \\
\text { percentile }\end{array}$ & Median & $\begin{array}{l}\text { 10th-90th } \\
\text { percentile }\end{array}$ & & Median & $\begin{array}{l}\text { 10th-90th } \\
\text { percentile }\end{array}$ & Median & $\begin{array}{l}\text { 10th-90th } \\
\text { percentile }\end{array}$ \\
\hline \multicolumn{11}{|l|}{ Age (years) } \\
\hline$<46$ & 1605 & 30.6 & $19 \cdot 5-42 \cdot 0$ & $23 \cdot 6$ & $12 \cdot 4-61 \cdot 0$ & 556 & $12 \cdot 0$ & $9 \cdot 0-14 \cdot 0$ & 6.8 & $4.5-11.9$ \\
\hline $46-55$ & 1204 & 29.0 & $18 \cdot 9-41 \cdot 4$ & $23 \cdot 3$ & $13 \cdot 0-70 \cdot 0$ & 448 & 11.3 & $8 \cdot 3-14.5$ & $7 \cdot 0$ & $4 \cdot 4-12 \cdot 6$ \\
\hline$>56$ & 1066 & $28 \cdot 0$ & $17.8-41.4$ & $23 \cdot 4$ & $12 \cdot 8-64 \cdot 0$ & 393 & 11.5 & $8.5-14.5$ & $7 \cdot 1$ & $4.5-11.9$ \\
\hline \multicolumn{11}{|l|}{ Sex } \\
\hline Male & 1909 & $29 \cdot 3$ & $17 \cdot 8-43 \cdot 5$ & $23 \cdot 3$ & $13 \cdot 1-60 \cdot 1$ & 615 & $12 \cdot 0$ & $9 \cdot 0-14 \cdot 7$ & $7 \cdot 2$ & $4.6-13 \cdot 0$ \\
\hline Female & 1991 & $29 \cdot 6$ & $19.5-39.8$ & $24 \cdot 0$ & $12 \cdot 3-70 \cdot 7$ & 791 & 11.5 & $8 \cdot 3-14 \cdot 0$ & $6 \cdot 7$ & $4.4-11 \cdot 6$ \\
\hline \multicolumn{11}{|l|}{ Residence } \\
\hline Urban & 2714 & $30 \cdot 6$ & $19.5-43.5$ & $27 \cdot 9$ & $13 \cdot 2-84 \cdot 1$ & 1020 & 11.5 & $8 \cdot 5-14.0$ & $6 \cdot 8$ & $4 \cdot 4-12 \cdot 6$ \\
\hline Rural & 1186 & $27 \cdot 2$ & $16 \cdot 6-36 \cdot 7$ & $18 \cdot 7$ & $12 \cdot 0-32 \cdot 1$ & 386 & $12 \cdot 0$ & $9 \cdot 0-15 \cdot 0$ & $7 \cdot 1$ & $4.7-11 \cdot 1$ \\
\hline \multicolumn{11}{|l|}{ Education } \\
\hline Illiterate & 180 & $28 \cdot 2$ & $18 \cdot 9-38 \cdot 6$ & $23 \cdot 6$ & $12 \cdot 7-59 \cdot 6$ & 60 & $11 \cdot 0$ & $8 \cdot 0-13 \cdot 5$ & $6 \cdot 0$ & $4 \cdot 1-10 \cdot 2$ \\
\hline Primary/middle & 1420 & $28 \cdot 7$ & $17 \cdot 2-39 \cdot 6$ & $22 \cdot 2$ & $13 \cdot 0-71.9$ & 482 & $11 \cdot 3$ & $8 \cdot 3-14 \cdot 0$ & 6.9 & $4.5-11.9$ \\
\hline Secondary education & 1710 & $29 \cdot 6$ & $19 \cdot 4-42 \cdot 1$ & 25.4 & $13 \cdot 6-62 \cdot 6$ & 615 & 11.5 & $8 \cdot 5-14 \cdot 3$ & $7 \cdot 4$ & $4 \cdot 6-13 \cdot 2$ \\
\hline University graduate & 586 & $31 \cdot 2$ & $20 \cdot 4-45 \cdot 2$ & $21 \cdot 2$ & $9 \cdot 6-59.2$ & 246 & $12 \cdot 7$ & $9 \cdot 5-15 \cdot 0$ & $6 \cdot 3$ & $4 \cdot 4-10 \cdot 8$ \\
\hline \multicolumn{11}{|l|}{ Religion } \\
\hline Hindu & 1867 & $31 \cdot 2$ & $20 \cdot 1-44 \cdot 0$ & $26 \cdot 3$ & $12 \cdot 5-83 \cdot 0$ & 808 & $12 \cdot 0$ & $9 \cdot 0-14.5$ & $7 \cdot 0$ & $4.5-11 \cdot 8$ \\
\hline Muslim & 809 & $26 \cdot 0$ & $16 \cdot 6-34.9$ & $20 \cdot 4$ & $12 \cdot 8-58 \cdot 1$ & 218 & $11 \cdot 3$ & $8 \cdot 5-14.0$ & 6.9 & $4.5-10 \cdot 4$ \\
\hline Christian & 770 & 28.4 & $17 \cdot 8-39 \cdot 1$ & $20 \cdot 2$ & $13 \cdot 3-40 \cdot 2$ & 113 & 11.0 & $7 \cdot 3-14 \cdot 7$ & $7 \cdot 0$ & $5 \cdot 0-12 \cdot 8$ \\
\hline Sikh & 149 & 32.5 & $22 \cdot 3-49 \cdot 0$ & $16 \cdot 0$ & $8 \cdot 0-35 \cdot 1$ & 104 & 12.5 & $10 \cdot 0-14 \cdot 0$ & $5 \cdot 7$ & $4.2-8.9$ \\
\hline Buddhist & 262 & 31.5 & $16 \cdot 2-43 \cdot 1$ & $42 \cdot 8$ & $27 \cdot 4-70 \cdot 5$ & 147 & $10 \cdot 3$ & $8 \cdot 0-12 \cdot 8$ & $9 \cdot 2$ & $4.7-15 \cdot 8$ \\
\hline \multicolumn{11}{|c|}{ Household monthly income (Indian rupees) } \\
\hline$<5000$ & 1911 & $27 \cdot 8$ & $17 \cdot 2-38 \cdot 0$ & $22 \cdot 3$ & $13 \cdot 6-58 \cdot 4$ & 595 & 11.3 & $8 \cdot 3-14 \cdot 0$ & $7 \cdot 1$ & $4 \cdot 6-12 \cdot 1$ \\
\hline $5000-10000$ & 1117 & $29 \cdot 6$ & $19 \cdot 0-41 \cdot 7$ & $27 \cdot 2$ & $14 \cdot 2-78.5$ & 397 & 11.5 & $8 \cdot 5-14 \cdot 7$ & $7 \cdot 6$ & $4 \cdot 7-13 \cdot 0$ \\
\hline$>10000$ & 871 & 33.8 & $22 \cdot 3-47 \cdot 8$ & $21 \cdot 8$ & $8.9-64.0$ & 414 & $12 \cdot 3$ & $9 \cdot 0-14.5$ & $6 \cdot 2$ & $4 \cdot 3-10 \cdot 8$ \\
\hline
\end{tabular}

${ }^{*}$ Recalls with large gaps were excluded. Recall values for each individual were averaged across their recalls. 
Table 3. Top five food item contributors from the diet history questionnaire to nutrient values by region

\begin{tabular}{|c|c|c|c|c|c|c|}
\hline \multirow[b]{2}{*}{ Nutrients } & \multicolumn{2}{|l|}{ Delhi } & \multicolumn{2}{|l|}{ Trivandrum } & \multicolumn{2}{|l|}{ Mumbai } \\
\hline & Food & $\%$ & Food & $\%$ & Food & $\%$ \\
\hline \multirow[t]{5}{*}{ Total energy } & Roti & 28.5 & Rice, white milled & $35 \cdot 3$ & Roti & $13 \cdot 7$ \\
\hline & Potato curry & 4.7 & Fresh-fish curry & $6 \cdot 8$ & Rice, white milled & $8 \cdot 6$ \\
\hline & Rice, basmati & 4.4 & Puttu & $5 \cdot 0$ & Oil, groundnut & 4.4 \\
\hline & Ghee & $4 \cdot 1$ & Rice, brown & 4.7 & Green gram & $4 \cdot 3$ \\
\hline & Curd & $2 \cdot 6$ & Potato curry & 3.2 & Sugar & $3 \cdot 3$ \\
\hline \multirow{5}{*}{ Protein } & Roti & $20 \cdot 2$ & Fresh-fish curry & 29.3 & Fresh-fish curry & $9 \cdot 7$ \\
\hline & Curd & $7 \cdot 3$ & Rice, white milled & $19 \cdot 6$ & Roti & $8 \cdot 6$ \\
\hline & Double-toned milk & 5.9 & Fresh-fish fry & 4.3 & Green gram & $6 \cdot 3$ \\
\hline & Potato curry & 5.8 & Chicken curry & 3.6 & Rice, white milled & $5 \cdot 2$ \\
\hline & Mutton curry & $3 \cdot 1$ & Dosa & $3 \cdot 1$ & Dahl (green/mung) & $5 \cdot 1$ \\
\hline \multirow{5}{*}{ Total fat } & Roti & 23.2 & Potato curry & 9.4 & Roti & 11.6 \\
\hline & Ghee & $10 \cdot 0$ & Coconut chutney & $9 \cdot 4$ & Oil, groundnut & $11 \cdot 2$ \\
\hline & Potato curry & $7 \cdot 8$ & Fresh-fish curry & 8.6 & Potato curry & 4.4 \\
\hline & Matar paneer & 4.3 & Puttu & $6 \cdot 0$ & Eggplant bhaji & 3.6 \\
\hline & Aloo methi & $2 \cdot 8$ & Avial & 4.8 & Oil, sunflower & 3.5 \\
\hline \multirow{5}{*}{ Carbohydrate } & Roti & $35 \cdot 7$ & Rice, white milled & 50.5 & Roti & 17.4 \\
\hline & Rice, basmati & 7.9 & Rice, brown & $6 \cdot 4$ & Rice, white milled & $15 \cdot 8$ \\
\hline & Sugar & $4 \cdot 1$ & Puttu & $5 \cdot 2$ & Green gram & $7 \cdot 2$ \\
\hline & Rice, white milled & 3.4 & Sugar & 3.4 & Sugar & $7 \cdot 2$ \\
\hline & Curd & 2.5 & Banana & $3 \cdot 1$ & Dahl, red gram & $2 \cdot 9$ \\
\hline \multirow{5}{*}{ Cholesterol } & Ghee & $22 \cdot 9$ & Fresh-fish fry & $19 \cdot 2$ & Egg scrambled/bhurji & $17 \cdot 2$ \\
\hline & Egg (boiled) & 9.9 & Egg curry & $18 \cdot 0$ & Egg (omelette) & 11.5 \\
\hline & Egg (omelette) & $9 \cdot 3$ & Mother dairy token milk & $11 \cdot 2$ & Egg (boiled) & $9 \cdot 8$ \\
\hline & Palak paneer & $6 \cdot 2$ & Milk, cow & $7 \cdot 3$ & Mutton curry & 8.8 \\
\hline & Mutton curry & $5 . \overline{5}$ & Tea & $6 \cdot 4$ & Egg curry & 7.5 \\
\hline \multirow[t]{5}{*}{$\mathrm{Ca}$} & Curd & $19 \cdot 3$ & Mother dairy token milk & $11 \cdot 2$ & Double-toned milk & 14.9 \\
\hline & Double-toned milk & $16 \cdot 0$ & Rice, white milled & $10 \cdot 3$ & Palak bhaji & $8 \cdot 8$ \\
\hline & Roti & $6 \cdot 6$ & Tea & $9 \cdot 1$ & Tea & $6 \cdot 9$ \\
\hline & Milk, buffalo & $5 \cdot 1$ & Fresh-fish curry & 8.8 & Milk, cow & $6 \cdot 9$ \\
\hline & Full-cream milk & 3.8 & Milk, cow & $7 \cdot 3$ & Curd & 4.5 \\
\hline \multirow[t]{5}{*}{$\mathrm{Fe}$} & Roti & $22 \cdot 2$ & Rice, white milled & $36 \cdot 2$ & Rice, white milled & 8.9 \\
\hline & Aloo methi & $5 \cdot 8$ & Fresh-fish curry & $18 \cdot 1$ & Roti & 8.4 \\
\hline & Rice, basmati & $5 \cdot 7$ & Puttu & 4.3 & Green gram & 8.2 \\
\hline & Potato curry & 4.0 & Dosa & 3.2 & Fresh-fish curry & 5.5 \\
\hline & Chole & 3.3 & Kadala & 2.6 & Palak bhaji & 4.7 \\
\hline \multirow[t]{5}{*}{ Vitamin A (retinol equivalents) } & Palak bhaji & 23.9 & Fresh-fish curry & $18 \cdot 1$ & Palak bhaji & $42 \cdot 6$ \\
\hline & Ghee & $10 \cdot 0$ & Cheera thoran & $15 \cdot 0$ & Dudhi bhopla bhaji & 13.5 \\
\hline & Double-toned milk & $7 \cdot 8$ & Carrot thoran & 14.0 & Liver & 4.6 \\
\hline & Palak paneer & 6.5 & Beef curry & $6 \cdot 3$ & Carrot & $4 \cdot 3$ \\
\hline & Aloo methi & $6 \cdot 2$ & Chicken curry & $5 \cdot 5$ & Double-toned milk & $4 \cdot 3$ \\
\hline \multirow[t]{5}{*}{ Vitamin $B_{1}$} & Rice, basmati & 11.4 & Rice, white milled & 55.4 & Rice, white milled & 14.4 \\
\hline & Rice, white milled & $4 \cdot 8$ & Fresh-fish curry & $6 \cdot 7$ & Green gram & $13 \cdot 1$ \\
\hline & Green gram & 4.4 & Rice, brown & $5 \cdot 4$ & Fried chana & $6 \cdot 5$ \\
\hline & Curd & 3.9 & Kanji rice & $2 \cdot 7$ & Dahl, red gram & $5 \cdot 2$ \\
\hline & Aloo ghobi & 3.6 & Idli & 2.5 & Vatana bhaji & 3.5 \\
\hline \multirow[t]{5}{*}{ Vitamin $B_{2}$} & Roti & 34.0 & Fresh-fish curry & $16 \cdot 5$ & Roti & $19 \cdot 0$ \\
\hline & Double-toned milk & $10 \cdot 7$ & Tea & $10 \cdot 2$ & Double-toned milk & $10 \cdot 1$ \\
\hline & Curd & $10 \cdot 0$ & Mother dairy token milk & 8.0 & Green gram & $7 \cdot 8$ \\
\hline & Tea & 3.0 & Puttu & $7 \cdot 1$ & Tea & $7 \cdot 7$ \\
\hline & Full-cream milk & 2.6 & Milk, cow & $5 \cdot 2$ & Milk, cow & 4.9 \\
\hline
\end{tabular}

SFA and trans-fatty acids) as well as refined carbohydrates and sugars $^{(33,36,37)}$.

Major strengths of the IHS and the design of nutritional component were the use of trained interviewers for conducing interviews at the participants' homes and the inclusion of three diverse regions of India. Using these methods, we were able to identify important aspects of dietary variability, such as unique and understudied regional foods and recipes in a population with a wide range of intakes and great access to food resources. However, it is important to note that our sampling scheme and recruitment methods ${ }^{(7)}$ may have decreased the external validity of the study population, as we did not include individuals in temporary housing or of very low socio-economic status from urban areas, due to potential issues with very limited dietary variability and major challenges with follow-up, particularly for medical outcomes ${ }^{(8)}$.

With the understanding that all dietary assessment instruments are subject to limitations and measurement error, the NINA-DISH software was developed to facilitate a multifaceted and comprehensive approach (i.e. DHQ, foodpreparer questionnaire and multiple 24HR) for measuring dietary intakes. Previous research has shown that such an approach is likely to improve the reliability of the overall estimates of intake by utilising the strengths of multiple dietary 
assessment methods ${ }^{(38)}$. While this would often be considered time- and cost-prohibitive, the computer-based NINA-DISH software proved to be efficient in terms of both data collection (front end) and analysis (back end) for the study staff. It is important to note that the NINA-DISH software was adapted and designed for use in a prospective epidemiological study of diet and cancer. Thus, priority was placed on capturing long-term or habitual diet and population variations, along with a reasonable estimate of individual intake. Previous analyses have demonstrated that the NINA-DISH dietary assessment tool successfully captures regional differences in dietary patterns ${ }^{(24)}$, as well as data on a wide range of and variation in intakes of various foods, nutrients, spices and oils across this diverse, middle-class population ${ }^{(7,25)}$. We realise that our nutrient database collated and modified from other international data sources is not optimal. However, given the limitations of what was available at the time, we feel that what we have created is both a vast improvement and urgently needed. Although the NINA-DISH software will need to be carefully validated in this and other South Asian populations, we met our initial objective to create a dietary assessment tool that was culturally appropriate and helpful to better understand the dietary habits of an understudied population at a high risk of developing chronic diseases. Our findings from the IHS nutritional component are intended to guide investigators in important aspects of designing dietary questionnaires and to provide useful insights for future studies within this and similar South Asian populations.

\section{Conclusion}

We developed and tested comprehensive dietary assessment tool and nutrient database to capture data on food and nutrient intakes within three diverse regions of India. We found that the computer-based NINA-DISH dietary software allowed the field interviewers of the IHS to successfully and efficiently collect dietary data via the DHQ and 24HR from the study participants in both urban and rural settings. We identified the preferred 'meal-based' approach and found informative differences in the number of food items reported at different times of the day and in the time needed to complete the DHQ and 24HR among different sociodemographic groups. While studying the major food contributors to nutrient intake across the regions, we identified many of the most important food items to assess within the Indian population. The NINA-DISH software can be relatively easily updated and modified and may provide a valuable resource for measuring dietary intakes in South Asian populations in other parts of the world, as well as among those who have recently immigrated to other countries, such as Canada, Fiji, Kuwait, Malaysia, Saudi Arabia, Singapore, the UK and the USA. Further research on Indian diet and lifestyle is urgently needed to develop targeted recommendations to address the emerging epidemics of chronic diseases as well as ongoing challenges of under- and overnutrition in India ${ }^{(2,34,39,40)}$.

\section{Supplementary material}

To view supplementary material for this article, please visit http://dx.doi.org/10.1017/S0007114513001864

\section{Acknowledgements}

We thank Novo Nordisk Pharma India Limited for permitting us to use and adapt the NINA software for the present study. We also thank all the participants and field investigators of the IHS. This research was supported by the Intramural Research Program of the National Institutes of Health, National Cancer Institute. The authors' responsibilities were as follows: C. R. D. was responsible for the statistical analysis, interpretation of results and writing of the manuscript; K. K. developed the diet assessment questionnaire, nutrient database and software and wrote the manuscript; M. J. M. was responsible for data analysis and writing; S. D.-J. developed the nutrient database and wrote the manuscript; $H$. S. developed the regionspecific diet assessment questionnaire and implemented the study; N. D. and P. S. G. were responsible for study implementation; S. H. developed the NINA-DISH software; A. M. was responsible for site-specific study coordination and implementation; R. S. designed and initiated the study and secured funding for the study, interpreted the results and wrote the manuscript. All authors were responsible for the critical review and approval of the final manuscript. None of the authors has a financial or personal conflict of interest.

\section{References}

1. Enas EA, Mohan V, Deepa M, et al. (2007) The metabolic syndrome and dyslipidemia among Asian Indians: a population with high rates of diabetes and premature coronary artery disease. J Cardiometab Syndr 2, 267-275.

2. Popkin BM, Horton S, Kim S, et al. (2001) Trends in diet, nutritional status, and diet-related noncommunicable diseases in China and India: the economic costs of the nutrition transition. Nutr Rev 59, 379-390.

3. Wild S, Roglic G, Green A, et al. (2004) Global prevalence of diabetes. Diabetes Care 27, 1047-1053.

4. Padmadas SS, Dias JG \& Willekens FJ (2006) Disentangling women's responses on complex dietary intake patterns from an Indian cross-sectional survey: a latent class analysis. Public Health Nutr 9, 204-211.

5. Rastogi T, Hildesheim A \& Sinha R (2004) Opportunities for cancer epidemiology in developing countries. Nat Rev Cancer 4, 909-917.

6. Rastogi T, Reddy KS, Vaz M, et al. (2004) Diet and risk of ischemic heart disease in India. Am J Clin Nutr 79, 582-592.

7. Sinha R, Daniel CR, Devasenapathy N, et al. (2011) Multicenter feasibility study evaluating recruitment, variability in risk factors and biomarkers for a diet and cancer cohort in India. BMC Public Health 11, 405.

8. Mathew A, Daniel CR, Ferrucci LM, et al. (2011) Assessment of follow-up, and the completeness and accuracy of cancer case ascertainment in three areas of India. Cancer Epidemiol 35, 334-341.

9. Sudha V, Radhika G, Sathya RM, et al. (2006) Reproducibility and validity of an interviewer-administered semi-quantitative food frequency questionnaire to assess dietary intake of 
urban adults in southern India. Int J Food Sci Nutr 57, 481-493.

10. Indian Council of Medical Research (1991) Report of Repeat Surveys (1988-1990). Hyderabad: National Institute of Nutrition.

11. Indian Council of Medical Research (1999) Report of Second Repeat Survey - Rural (1996-1997). Hyderabad: National Institute of Nutrition.

12. Gopalan C, Rama Sastri B \& Balasubramanian S (1989) Habitual Diets in India and Their Adequacy. Nutritive Value of Indian Foods. Hyderabad: National Institute of Nutrition.

13. Gopalan C, Rama Sastri BV, Balasubramanian SC, et al. (1989) Nutritive Value of Indian Foods, revised ed. Hyderabad: National Institute of Nutrition, Indian Council of Medical Research pp. 156.

14. Krishnaswamy K \& Polasa K (1995) Diet, nutrition \& cancer - the Indian scenario. Indian J Med Res 102, 200-209.

15. Krishnaswamy K \& Raghuramulu N (1998) Bioactive phytochemicals with emphasis on dietary practices. Indian $J$ Med Res 108, 167-181.

16. Krishnaswamy K, Goud VK, Sesikeran B, et al. (1998) Retardation of experimental tumorigenesis and reduction in DNA adducts by turmeric and curcumin. Nutr Cancer 30, 163-166.

17. Krishnaswamy K (1996) Indian functional foods: role in prevention of cancer. Nutr Rev 54, S127-S131.

18. Hebert JR, Gupta PC, Bhonsle RB, et al. (1998) Development and testing of a quantitative food frequency questionnaire for use in Kerala, India. Public Health Nutr 1, 123-130.

19. Hebert JR, Gupta PC, Mehta H, et al. (2000) Sources of variability in dietary intake in two distinct regions of rural India: implications for nutrition study design and interpretation. Eur J Clin Nutr 54, 479-486.

20. Pasricha S (1995) Count What You Eat [ICoMR, editor]. Hyderabad: National Institute of Nutrition

21. Pasricha S, Rebello LM \& Indian Council of Medical Research (1964) Some Common Indian Recipes and Their Nutritive Value, vol. viii, 113 p. Hyderabad: Nutrition Research Laboratories.

22. Kapur A, Kapur K \& Prakash W (1997) Computer aided interactive nutrition assistant - a unique tool for improving diabetes nutrition management. Diabetologia 40A, Suppl. 1, 1519 .

23. Subar AF, Thompson FE, Potischman N, et al. (2007) Formative research of a quick list for an automated selfadministered 24-hour dietary recall. J Am Diet Assoc 107, 1002-1007.

24. Daniel CR, Prabhakaran D, Kapur K, et al. (2011) A crosssectional investigation of regional patterns of diet and cardio-metabolic risk in India. Nutr J 10, 12.

25. Ferrucci LM, Daniel CR, Kapur K, et al. (2010) Measurement of spices and seasonings in India: opportunities for cancer epidemiology and prevention. Asian Pac J Cancer Prev 11, $1621-1629$
26. Zakaria I, Sabry L \& Rizek R (1982) Food composition tables for the near east. Food and Agricultural Organization of the United Nations and the US Department of Agriculture cooperative project, p. 275.

27. Subar AF, Midthune D, Kulldorff M, et al. (2000) Evaluation of alternative approaches to assign nutrient values to food groups in food frequency questionnaires. Am J Epidemiol 152, 279-286

28. Subar AF, Thompson FE, Kipnis V, et al. (2001) Comparative validation of the Block, Willett, and National Cancer Institute food frequency questionnaires: the Eating at America's Table Study. Am J Epidemiol 154, 1089-1099.

29. Subar AF, Ziegler RG, Thompson FE, et al. (2001) Is shorter always better? Relative importance of questionnaire length and cognitive ease on response rates and data quality for two dietary questionnaires. Am J Epidemiol 153, 404-409.

30. Thompson FE, Subar AF, Brown CC, et al. (2002) Cognitive research enhances accuracy of food frequency questionnaire reports: results of an experimental validation study. $J \mathrm{Am}$ Diet Assoc 102, 212-225.

31. Rao PV (2002) Dietary patterns and glucose intolerance among rural Indian populations. J Indian Med Assoc $\mathbf{1 0 0}$ $137-140$

32. Iqbal R, Ajayan $\mathrm{K}$, Bharathi AV, et al. (2009) Refinement and validation of an FFQ developed to estimate macro- and micronutrient intakes in a south Indian population. Public Health Nutr 12, 12-18.

33. Misra A, Khurana L, Isharwal S, et al. (2009) South Asian diets and insulin resistance. Br J Nutr 101, 465-473.

34. Shetty PS (2002) Nutrition transition in India. Public Health Nutr 5, 175-182.

35. Chatterjee P (2002) India sees parallel rise in malnutrition and obesity. Lancet 360, 1948.

36. Lawton J, Ahmad N, Hanna L, et al. (2008) 'We should change ourselves, but we can't': accounts of food and eating practices amongst British Pakistanis and Indians with type 2 diabetes. Ethn Health; 13, 305-319.

37. Singh RB, Rastogi SS, Rao PV, et al. (1997) Diet and lifestyle guidelines and desirable levels of risk factors for the prevention of diabetes and its vascular complications in Indians: a scientific statement of The International College of Nutrition. Indian Consensus Group for the Prevention of Diabetes. J Cardiovasc Risk 4, 201-208.

38. Carroll RJ, Midthune D, Subar AF, et al. (2012) Taking advantage of the strengths of 2 different dietary assessment instruments to improve intake estimates for nutritional epidemiology. Am J Epidemiol 175, 340-347.

39. Caballero B \& Popkin BM (editors) (2002) The Nutrition Transition: Diet and Disease in the Developing World. London: Elsevier Science/Academic Press.

40. Griffiths PL \& Bentley ME (2001) The nutrition transition is underway in India. J Nutr 131, 2692-2700. 